\title{
Regiliter.
}

Die 3iffern bebeuten bie Seitenzaht.

\section{A. Sadjregifter.}

Ybholung ber Dptionäurfunde 176, 180 . $\mathfrak{A} b$ ịtimmung gebetet $28,42,66,108$, $124,156,172,188,194$.

Y)htung 26, 28, 34.

Átnberung ber Gejebsebung 26, 34 .

Umt, öffentliches 110, 112.

Anfechtung Der Option 170, 176.

Angeftellte $\mathbf{4 2 .}$

Annahme ber Dptionsurtunbe 178.

Inorbnung bes Staates 42, 44, 98.

Anrufung 32.

Unịtalten, öffentlidge 110.

Unitellung 56, 116, 154 .

Uufenthalt 126, 194, 198.

- vorübergehender 210 .

Oufenthaltảgenehmigung 62, 124, 192 , $198,212$.

Aruflöjung ber çye 190.

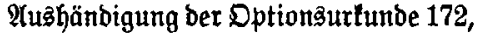
$176,178,180$.

Uนăländer 26, 102, 106, 108, 110, 112.

Uนålegung 112, 154, 178, 212, 240, 242 , $248,252$.

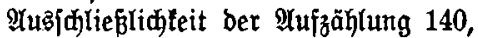
248.

Beamtenverhältnia $54,90,116,150$, $152,156,158,182,186$.

Oefähigungsెnađ̆toeiz 140.

Behorde 94, 96, 104, 208.

Beilegung 124, 182, 208.

Bereftigte 22, 28, 30, 32, 34 .

Beruf 102, 108, 138.

Beurlaubung 152, 156.
Botichafterfonferenz $20,28,30,246$, $248,250$.

Dienftberhältnis 94, 106, 108, 116.

- vertrag 70, 86, 90.

Einbürgerung 186.

Einfuhrfreiheit 214, 244, 250, 252. einjtweilige Entideibung 122.

Eintragung ins §onjulatsregifter 58,60 .

Eifenbahn 40, 42, 54, 98, 142, 184.

Entlajfung 46, 130.

Entjojäbigung 20, 26.

Crmädtigung 30.

Exnennung 56.

Erwerbştâtiglèt 102, 108.

Covolation 30, 92, 96, 212, 238, 240, 242.

Žeititellung 122, 196.

Flađ) $212,244,248,250$.

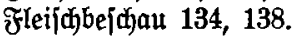

Frembenredt 108.

Friebersెverträge 18.

Gebührenfreiheit 40.

Beridfte 30, 56, 88, 90, 158, 240, 242.

Brejebgebung 26, 34 .

Sewerbetreibende 42.

(Srenzyetfehr 214, 244, 252.

häuallid)e (Gemeinf haft 184, 188, 190.

Fontitätałarte 66,68 .

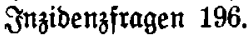

tonzeffioniertes Beroerbe 138.

̊ünbigung 42, 44, 70, 90, 92, 94, 98, $106,120,122$.

- sfrift 40.

Qanbesinjtanzen 2, 30, 34, 92.

- rebit 108. 


\section{- II -}

Lebenşverhältniffe 128.

Seihbeamte 152, 153.

Mragiftrat 70, 90, 92, 94, 116, 120.

Map̧nahmen einer Behörbe 64,68 , $86,92,94,96,100$.

Minberkeit 104.

- enredt 106, 140.

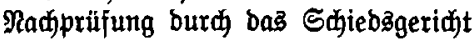
$158,242$.

natürliche Erzeugniffe $212,244,246$.

Nidhterjळöpjung ber Lanbesinjtanzen 34.

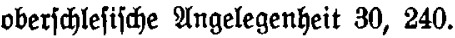

Optart 40,106, 176, 178, 180.

Dption 168, 174, 176, 178, 184, 190.

- Zhehudro 168, 176, 178.

- Sertflärung 160, 168, 180, 210.

- Şurfunde 170, 172, 176, 178.

ßaß̃ 124.

ßenjionierung 142.

ßolizei 130, 134.

Poit 46, 54.

ßrivatredt 42, 44, 86, 90, 92, 94.

Red)te 102, 112.

- auf lubernahme 54, 134.

- erworbene $2,20,22,24,28,34,36$, $40,54,56,134,158$.

- diffentlidise 98.

Ređ)țantprud 60.

- juhut 104.

- jtreitigfeit (bürgertiðe) 90 .

- verfolgung $26,34$.

$\Re$ öjtflad) 248.

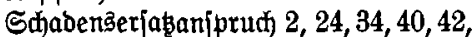
$46,130,134$.

- prifidt 26.

Shiebsageriðte, gemijate 18 .

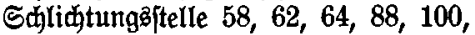
$124,182,206$.

Sdiwerpunft ber wirtidjaftlidjen und perjönliçen Beżiehungen 66,128 , $170,180,210$.

ธ() 62,64 .

- Der Minberheit 28, 106.

- bes $\mathfrak{3 0 h n b e r e d t i g t e n ~} 94,98$.

- biplomatifjer 28.

- ertoorbener Rectite 40.
Sonberbejtimmung 102, 110, 120 , $214,252$.

- redt 22.

Spebiteur 36, 42.

Staatzangehörigfeit $2,22,26,28,30$, $34,56,58,90,94,104,106,108$, $120,124,160,172,174,182,186$, 190.

- swechjel 128, 176, 184, 186, 188, 190, 194, 198, 210.

Staatsbeamte 132.

- verträge 54, 132, 176.

Stiditag 68, 132, 134.

Etreitigfeiten 104.

- pribater Ratur 28.

- Bfffentridy=redtliche 92.

Stroh 212, 242. 248, 250.

Tabatmonopol 2,36 .

ulbergang ber Staat3hokeit 40,42, 56 , $60,104,108,118,120,124,132$, $140,152,158,170,194,210$.

libernahme von Beamten $52,54,56$, $132,134,152,158$.

Ungültigf́eit ber Option 176.

Unterfommilfion Der Benfer Sonferenz 20.

Berfahrensorbnung 30,96.

Berlebung 96, 120, 140.

- bes 28 ohnredts $68,86,92,122$.

- erworbener $\Re$ echte $2,18,26,36,98$.

Berluft ber Staatāangehörighteit 60, 190, 196.

Beröffentlichung Der Entjđeidungen 30

Bertrag 36, 40, 42, 44, 90, 92, 98, 108, $118,140$.

Berwaltungäbehöroe 240.

- itreituerfahren 96.

Berzicht 56.

Bölferredht $18,22,30,32,54,94,132$, 158.

Meifungen ber vorgefeb̧ten Beḩorbe 96, 240.

Miberruf 140.

- ber Dptionకerflärung 160, 168, 190.

WBiener $\mathfrak{A b F m m e n ~ 1 9 0 , ~ 1 9 6 , ~} 198$.

Wohnen 68, 126.

Bohnterft 62, 64, 68, 70,90, 92, 98, 


\section{- III -}

$100,102,104,106,108,110,172$, $174,180,190,192,196,206,212$, $\mathfrak{B p h n j i s ~ 5 8 , 6 0 , 6 2 , ~ 6 6 , ~ 6 8 , ~ 1 0 4 , ~ 1 2 4 , ~}$ $126,170,180,188,196,210$. zeitweiliger Dient 152, 154, 156. Bollfreibeit 40, 214, 244, 250, 252. Bulaffung zu öffentlichen $\mathfrak{A n j t a l t e n} 110$, $112,114,120$.

— zu ỏffentliđen @imtern 110, 112, 114 .

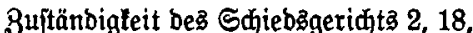
$20,28,30,34,40,44,56,62,64,86$, $88,90,92,96,100,106,108,140$, $156,190,192,196,198,206,208$, $212,244$.

- bet Sd)lidtungsitelle $86,92,100$ 208.

8uftellung 178, 180.

\section{B. Quellentregifter.}

2hotommen aber bie Erleid)terungen im lleinen Brenzberfehr vom 30. 12.

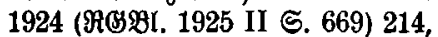
$244,252$.

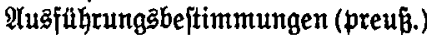
betr. Fleijdbejdau bom 20. 3. 1903 $138,140$.

Bejđhlū ber Botjałafterfonferenz vom 20. 10. $192120,28,246,248,250$. Bejd) 9. 3. 1922158.

Bürgerlicher (Sejefbud): $§ 26942$. Senfer भbfommen:

Ât. $4 \quad 20,24,26,28,34,40,42$, $44,56,58,98,138,140$, $150,158$.

Urt. $5 \quad 2,20,22,24,28,30,32$, $34,40,150,158$.

Irt. $25124,128,182,188,196$, 210.

Ulrt. $2658,60,62,196$.

Art. 27174.

भrt. $29 \quad 62,66,70,122,126,170$,

भivt. $30 \quad 210$.

2Ixt. 31 182, 184, 186, 188, 190,

2rxt. $32 \quad 190$.

Urt. $40 \quad 68,104$.

Irt. $41 \quad 174,180,190,192,194$,

Yxt. $42 \quad 190,196$.

政. $4368,70,90,92,102,108$,

2rrt. $45 \quad 204$. $180,194$. 194. $196,198,208,212$.

$\mathfrak{A r t .} 48$

भirt. 49

Irt. 50

2(rt. 53

2̂̃rt. 55

2rrt. 56

Irt. 57

Uxt. 58

Urt. 59

Art. 67

Urt. 74

भixt. 77

Art. 82

Art. 147

2rrt. 158

भirt. 217

art. 218

Art. 219

2Irt. 220

भrt. 224

भirt. 226

भirt. 233

थrt. 238

2)rt. 241

2⿰rt. 305

Irt. 501 110,120 .
$160,170,176$.

$160,172,176,180$.

$176,178,180$.

176.

40, 208.

$58,62,64,70,86,88,92$, $94,96,100,176,196$, 208.

208.

$58,64,86,90,92,124$, $196,206,208$.

96,122 .

112.

104.

$70,92,110,112,114$.

$70,88,90,92,100,104$, $106,108,110,112,114$, 120.

104.

92.

252.

$212,214,242,244,246$, $248,250,252$.

252.

252.

252.

$214,250,252$.

252.

252.

252 ,

$66,68$.

$40,142,152,154,156$, 158.

Art. $505 \quad 152,154,184$.

2rt. 519154. 
थrt. 54240 .

Irt. 543 152, 154.

2rrt. 544 40, 142, 150, 154, 156, 158.

शrt. $545 \quad 40,154$.

Art. 554150.

Urt. 55840.

צ्At. 563198.

Qrt. $588 \quad 30,92,96,238,242$.

अrt. 590 34, 92, 234

Urt. 59230.

צrt. 59632.

Yrt. 597 32, 88, 90, 92 .

צrt. 60534.

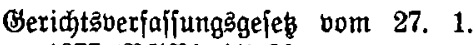

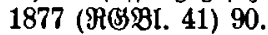

(Sefes tiber bie poln. Staatsangeförig.

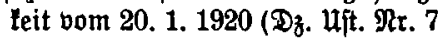
多. 44) 56, 60, 62, 186.

Bewerbeorbnung 138.
Minberheitenbertrag vom 28, 6. 1919 112.

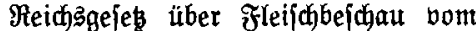

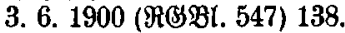

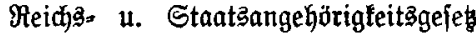

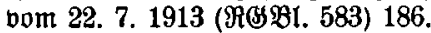

Stäoteoronung vom 31. 5. $185394,96$.

Berfahrentaronung besె Sxhiebsgeridhts für Dberfaflefient bom 9. 3. 192326 , 232.

Berorbnung betr. Bumiderhattblungen gegen bie \$aß̧borfariften bom

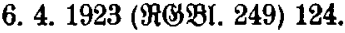

Berjailler Friedenb̧ertrag: צrt. 25620.

Wiener $\mathfrak{A b l o m m e n ~ b o m ~ 3 0 . ~ 8 . ~} 1924$ $190,196,198$.

Bivilprozę́oronung 178

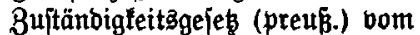
1. 8.1883 (ङ. ङ. 237) 96.

\section{A. Skorowidz.}

Liczby oznaczaja strony.

Akt opcji 171, 173, 177, 179.

badanie mięsa 135, 139.

cudzoziemcy 27, 103, 107, 109, $111,113$.

deklaracja opcyjna 161, 169, 181, 211.

dochodzenie prawa $27,35$.

dopuszczenie do urzędów publ. $111,113,115$.

- do zakładów publ. 111, 113, $115,121$.

doręczenie 179, 181.

dowód uzdolnienia 141.

ewokacja 31, 93, 97, 213, 239, 241, 243.

funkcjonarjusz 43 .

incydentalne zagadnienia 197.

instancje krajowe $3,31,35,93$. instrukcja wladzy przelozionej 97. karta identyczności 67, 69.

koleje 41, 42, 55, 99, 143, 185. komisja polubowna $59,63,65$, 89, 101, 125, 183, 207.

konferencja ambasadorów 21, 29, $31,247,249,251$.

konwencja wiedeńska 191, 197, 199.

len $213,245,249,251$.

- suszony 249.

magistrat $71,91,93,95,117,121$.

miejsce zamieszkania $59,61,63$, $67,69,105,125,127,171,181$, $189,195,211$.

mniejszość 105.

monopol tytoniowy 3,37 .

nadanie obywatelstwa 187.

naruszenie 97, 121, 141.

- praw nabytych $3,19,27,37$, 99.

- prawa zachowania zamieszkania $69,87,93$.

nieważność opcji 177. 
niewyczerpanie instancyj krajowych 35 .

nominacja 57, 117, 155.

obowiazek odszkodowania 27.

obszar plebiscytowy 29, 43, 67, 109, 125, 157, 173, 189, 195.

obywatelstwo $3,23,27,29,31$, $35,57,59,91,95,105,107$, $109,121,125,161,173,175$, $183,187,191$.

ochrona 63,65 .

- dyplomatyczna 29.

- mniejszości 29, 107.

- prawna 105.

- praw nabytych 141.

- uprawnionych do zachow. zam. 95, 99.

odwolalność 141.

odwolanie 33.

- deklaracji opcyjnej 161, 169, 191. odszkodowanie 21, 27.

opcja 169, 175, 177, 181, 185, 191. optant 41, 107, 177, 179, 181. orzeczenie tymczasowe 123.

ośrodek stosunków osobistych i gospodarczych $67,129,171$, $181,211$.

paszporty 125.

płody naturalne 213, 245, 247.

pobyt 127, 245, 247.

- przejściowy 211.

poczta 47,55 .

podjęcie aktu opcji 177, 181.

podkomisje konferencji genewskiej 21.

policja 43, 45, 99.

postepowanie sporno-administracyjne 97.

posiadacz prawa 23, 29, 31, 33.

posiadanie mieszkania 69, 127.

postanowienie państwa $43,45,65$, $87,93,95,97,99$.

prawo $105,113$.

- do przejęcia 55, 135.

- krajowe 109.

- międzynarodowe 19, 23, 31, $33,55,95,133,159$. pravo mniejszości 141.

- nabyte 3, 21, 23, 25, 29, 35, $37,41,55,57$.

- prywatne 43, 45, 87, 91, 93, 95.

- publiczne 99.

- szczególne 23.

- zachowania zamieszkania 63 , $65,69,71,91,93,99,101,103$, $105,107,109,111,173,175$, 181, 191, 193, 197, 207, 213. przedsiębiorca 43.

przejẹcie urzędników $53,55,57$, $133,135,153,159$.

przejście suwerenności 41, 43, 57, $61,105,109,119,121,125$, $133,141,153,159,171,195$, 211.

przemysł koncesjonowany 139.

przeniesienie $w$ stan spoczynku 143.

przepis szczególny 253.

przyjęcie aktu opcji 179.

przyzwolenie Tryb. Rozjem. 31.

publikacja orzeczeń 31 .

regulamin procesowy $33,97$.

rezygnacja 57.

roszczenie odszkodowawcze 3,25 , $35,41,43,47,131,135$.

- prawne 61.

rozpoznawanie przez Tryb. Rozjem. 159, 243.

rozwiąanie małżeństwa 191.

ruch graniczny $215,245,253$.

sady 31, 57, 89, 91, 159, 241, 243. stoma 213, 245, 249, 251.

slużba czasowa 153, 155, 157.

spedytor 37,43 .

spór 105.

- prywatno-prawny 29, 91.

- publiczno-prawny 93.

sprawa górnoślaska 31, 241.

stosunek służbowy $55,70,91$, $95,109,117,151,153,157$, $183,187$.

stosunki życiowe 129.

traktaty pokoju 19. 


\section{$-\mathrm{VI}-$}

trybunały rozjemcze mieszane 19. umowa $37,41,43,45,91,93,99$, $109,119,141$.

- międzypaństwowa 55, 133,177, - shuźbowa 87, 91.

urlop 153, 157.

urząd publiczny 111, 113.

urzędnik państwowy 133 .

- wypożyczony 153, 155.

ustalenie 123, 197.

ustawodawstwo 27,35 .

uszanowanie praw 27, 29, 35.

utrata obywatelstwa 61, 191, 197.

władza 95, 97, 105, 209.

- administracyjna 241.

- opcyjna 169, 177, 179.

właściwość Komisji Polubownej $87,93,101,209$.

- Trybunatu Rozjemczego 3, 19, $21,29,31,35,41,45,57,63$, $65,87,89,91,93,97,101,107$, $109,141,159,191,193,197$, 199, 207, 209, 213, 245.

wolność od cła 41, 215. wolnosć od opłat 41

- wwozu 215, 245, 251, 253.

wręczenie aktu opcji 173,177, 179, 181.

wspólność domowa 185, 189, 191. wykładnia 113, 155, 179, 213, 241, $243,249,253$.

wyliczenie wyczerpujace 141, 249. wypowiedzenie $43,45,71,91,93$, 95, 99, 109, 121, 123.

termin wypowiedzenia 41 .

zaczepienie opcji 171, 177.

zakłady publiczne 111 .

zalatwienie sporu 125, 183, 209.

zarejestrowanie w konsulacie 59 , 61.

zarobkowanie 103, 109 .

zawód 103, 109, 139.

zezwolenie na pobyt $63,125,193$, $199,213$.

zmiana obywatelstwa 129,177, $185,187,189,191,195,199,211$

- ustawodawstwa 27, 35.

zwolnienie 47, 131.

\section{B. źródla.}

Decyzja Konferencji Ambasadorów z 20.10.1921 r. 21, 29, $247,249,251$.

Kodeks cywilny: $§ 26943$.

Konwencja Genewska:

$\begin{array}{ll}\text { art. } 4 & 21,25,27,29,35,41 \\ & 43,45,57,59,99, \\ & 139,141,151,159 . \\ \text { art. } 5 & 3,21,23,25,29,31,33 \\ & 35,41,151,159 . \\ \text { art. } 25 & 125,129,183,189, \\ & 197,211 . \\ \text { art. } 26 & 59,61,197 . \\ \text { art. } 27 & 175 . \\ \text { art. } 29 & 63,67,69,123,127, \\ & 171,181,195 . \\ \text { art. } 30 & 211 . \\ \text { art. } 31 & 183,185,187,189 \\ \text { art. } 32 & 191,195 .\end{array}$

art. $40 \quad 69,105$.

art. $41175,181,191,193$, $195,197,199,209$, 213.

art. $42 \quad 191,197$.

art. $4369,71,91,93,103$, $109,111,121$.

art. $48 \quad 161,171,177$.

art. $49161,173,177,181$.

art. $50177,179,181$.

art. 53177.

art. $55 \quad 41,209$.

art. $5659,63,65,71,87,89$, $93,95,97,99,101$, $177,197,209$.

art. 57209.

art. $5859,65,87,91,93,125$, 197, 207, 209.

art. $5997,123$.

art. 67.113 


\section{- VII -}

\begin{tabular}{|c|c|}
\hline $\begin{array}{l}\text { art. } 74 \\
\text { art. } 77 \\
\text { art. } 82\end{array}$ & $\begin{array}{l}71,93,111,113,115 . \\
71,89,91,93,101 \\
105,107,109,111 \\
113,115,121 .\end{array}$ \\
\hline art. 147 & 105. \\
\hline art. 158 & 93. \\
\hline art. 217 & 253. \\
\hline art. 218 & $\begin{array}{r}213,215,243,245, \\
247,249,251,253 .\end{array}$ \\
\hline art. 219 & 253. \\
\hline art. 220 & 253. \\
\hline art. 224 & 253. \\
\hline art. 226 & $215,251,253$ \\
\hline art. 233 & 253. \\
\hline art. 238 & 253. \\
\hline art. 241 & 253. \\
\hline art. 305 & 67, 69 . \\
\hline art. 501 & $\begin{array}{l}41,143,153,155,157 \\
159 .\end{array}$ \\
\hline art. 503 & 149. \\
\hline art. 505 & $153,155,185$ \\
\hline art. 519 & 155. \\
\hline art. 542 & 41. \\
\hline art. 543 & 153,155 \\
\hline art. 544 & $\begin{array}{l}41,143,151,153,155 \\
\quad 157,159 .\end{array}$ \\
\hline art. 545 & 41,155 \\
\hline art. 554 & 151. \\
\hline art. 558 & 41. \\
\hline art. 563 & 199. \\
\hline $\begin{array}{l}\text { art. } 588 \\
\text { art. } 590\end{array}$ & $\begin{array}{l}31,93,97,239,243 . \\
35,93,235 .\end{array}$ \\
\hline art. 591 & $\begin{array}{l}83,90,200 \\
83 .\end{array}$ \\
\hline art. 592 & 31. \\
\hline art. 596 & 33. \\
\hline & $33,89,91,93$. \\
\hline
\end{tabular}

art. 60535 .

Konwencja o ulatwieniach w malym ruchu graniczn ym z 30.12. $1924215,245,253$.

Konwencja Wiedeńska z 30.8 . 1924 r. 191, 197, 199.

Ordynacja miejska z 31. 5. 1853 r. $95,97$.

Ordynacja przemyslowa 139.

Procedura cywilna 179.

Regulamin procesowy Tryb. Rozjem. z 9. 3. 1923 r. 27, 233.

Rozporządzenie (niem.) w sprawie występków paszportowych z 6. 4. 1923 r. (RGBl. 249) 125.

Rozporzadzenia wykonawcze (pruskie) w sprawie badania mięsa z 20. 3. 1903 r. 139, 141.

Traktat o mniejszościach z 28. 6 . 1919 r. 113.

Traktat Wersalski: art. 25621.

Uchwala Rady Ministrów z 9. 3. 1922 r. 159.

Ustawa o obywatelstwie (niem.) z 22. 7.1913 r. (RGBl. 583) 187.

Ustawa o obywatelstwie $\mathrm{z} 20.1$. 1920 r. (Dz. Ust. Nr. 7 p. 44) $57,61,63,187$.

Ustawa o ustroju sądownictwa $z$ 27. 1. 1877 r. (RGBl. 41) 91.

Ustawa o wlaściwości (prus.) z 1. 8. 1883 r. (G. S. 237) 97.

Ustawa (niem.) w sprawie badania mięsa z 3.6.1900 r. (RGBl. 547) 139 .

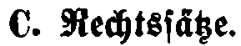

Steiner und Brop:

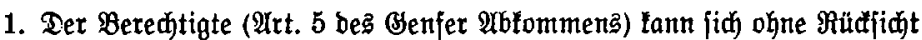
auf feine Staatåangehörigleit an bas Sdjiebsgeridyt für Dberfdlefien wenden.

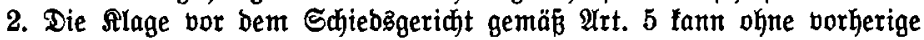
Anrufung anderer צnjtanzen erkoben werben.

3. Der $2 \mathfrak{d r t} 4$ beş Benfer $\mathfrak{u b f o m m e n s ~ e n t h a ̈ l t ~ b i e ~ m a t e r i e l l = r e c h t l i c h e ~ \Re e g e : ~}$

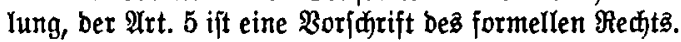




\section{- VIII -}

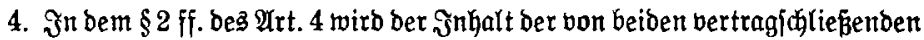

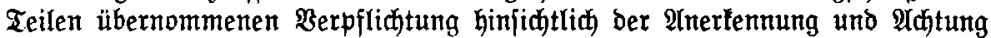

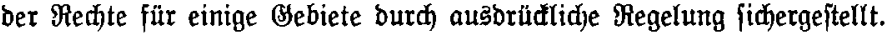

5. Den Brotofollen Der Unterfommifíionen Der Benfer Ronferenz tann

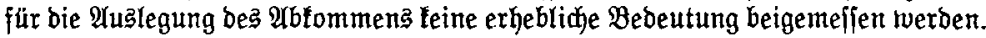

Rajunty:

Die bom Staate auf (Grunb eines privatredttlidhen Bertrages augge(prod)ente

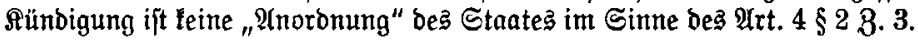

Frofýtati :

1. Gine Berpflidftung bes ein Bebiet übernebmenden Staates auf liber= nahme ber auf biejem Bebiete bejđäftigten Beamten bejteht nidht.

2. Das Benfer $\mathfrak{A b f o m m e n ~ e n t h a ̈ l t ~ f e i n e ~ B e f f t i m m u n g ~ u ̈ b e r ~ b i e ~ l a ̈ b e r n a h m e ~}$ von ßoftbeamten.

Dr. $\mathfrak{B r u t :}:$

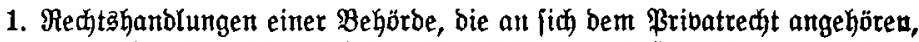

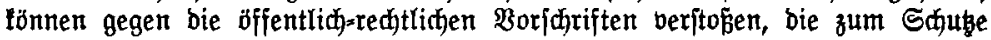
ber Wohnberectigten gegeben find.

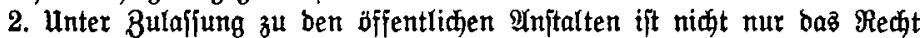

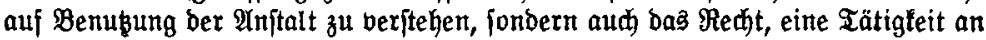
ber Injtalt auşzuйben.

Salamoba:

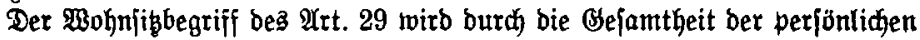

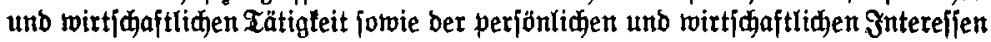
beftimmt, bie als eine Eingeit aufăfaffen fino.

Difromali :

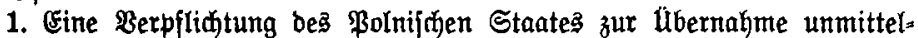
barer Staatabeamten ift im Benfer 2 rbfommen nifht ausgefprodfen.

2. Mangel einer ausbridutlif getroffenen Bereinbarung befteht nach Böffer, redit teine Berpflidtung, Beamten bes abgetretetten Bebietż zu übernehmen.

Bollng:

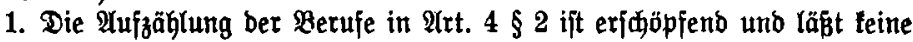
2uabehnung zu.

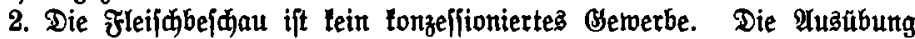

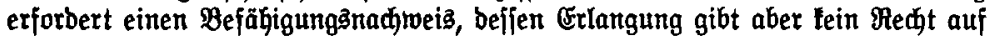

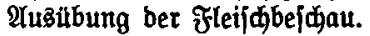

3. Bur ßrufung, ob eine Berlekung eineas Minberheitarechts vorliegt, ift bas

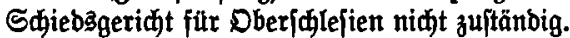

Pufiolit :

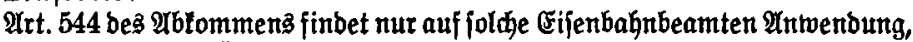
bie bor ihrem ftäntbigen ûbertritt in ben pornifden Staat3bienjt zeitweilige Beamte im Sinne bon $\mathfrak{A r t}$. 501 u. ff. bes atbtommens getwefen find.

Dpperzborff:

Eine Dption hat teine redtlidhe $\mathfrak{B i r f u n g}$, wenn igr Mibertuf nod bor ber Option felbft bei ber Bełörbe eingegangen ifft.

Grufdifa :

1. Das $\mathfrak{B e j e n}$ Der Option befteht in ber Erftärung beả Dptanten.

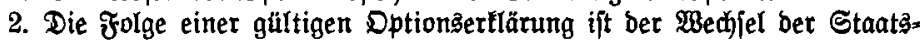




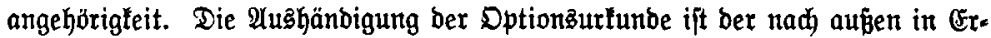
他einung tretenbe Beitpunlt Der Feftitellung ber Bultigleit Der Dption. Die Rishtabholung ber Optionsurfunbe ift für bie Bültigleit ber Sption belanglos.

Reumann:

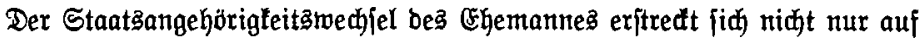
bie (Ehefrau (2rt. 31), jonbern aubi) auf beren mit ifr lebente minberjäłrige Ainber einer fruberen she.

Folger:

Bei Regelung ber Staatåangehörigfeit ber Ehejrau auf Brunb bes Genjer Abtommens ift bas Beftehen ber häuslidgen Bemeinjđaft nidjt entideident.

Grref:

1. Fü ein Serfahren auf Feftittellung ber Staatsangehörigfeit, bas fich auf

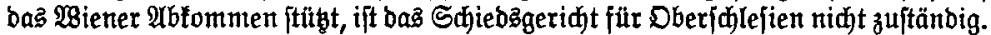

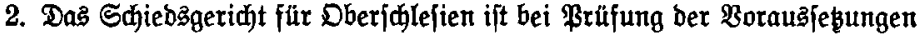

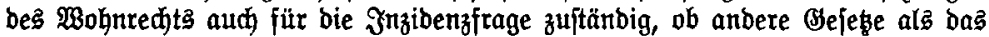
Genfer $\mathfrak{A} b$ fommen arzumenden fint.

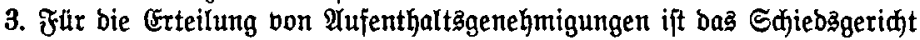
für Dberjoblejien niđt zuftäntbig.

Sonel:

Brwed ber Erridtung ber Sdylidhtungștelle ift bie Beilegung ber Streitig. teit; bie Streitigfeit ift beigelegt, wenn bie Beteiligten fid mit ber von ber Sdylid)=

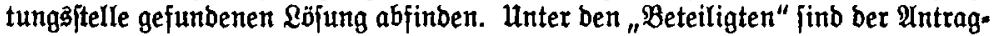
fteller unb bie feinen $\mathfrak{A n}$ \{prudi nicht anerfentenbe Behörbe zu verftehen.

\section{Sianef:}

1. Bejaht bas Beridht (Berwaltungäbehörbe) bie Frage, baß̄ feine Ent=

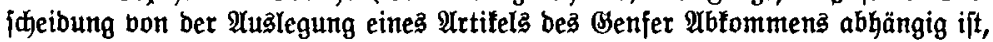

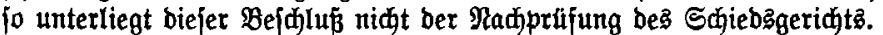

2. Crgibt fich aus ber Darlegung bes Sadjoerhalts in ber Evolationajfarift,

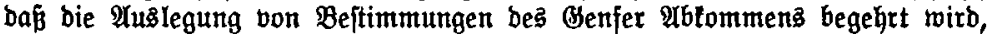

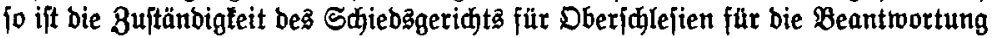
ber fragen gegeben.

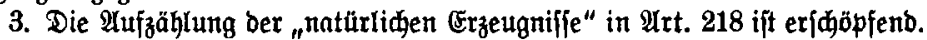

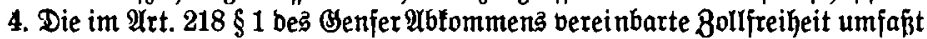
nibt bie Einfuhrfeiheit.

\section{c. Tezy.}

\section{Steiner i Gross:}

1. Posiadacz prawa (art. 5 Konwencji Genewskiej) może zwrócić się do Trybunału Rozjemczego dla Górnego Śląska bez względu na swe obywatelstwo.

2. Skarge przed Trybunalem Rozjemczym w myśl art. 5 można wytoczyć bez uprzedniego odwołania się do innych instancyj.

3. Art. \& Konwencji Genewskiej zawiera normę materjalnoprawna, art. 5 przepis prawa formalnego.

4. W $\S 2$ i nast. art. 4 ustalono przez wyraźne unormowanie 


\section{$-\mathrm{X}-$}

zakres zobowiązań obydwóch układających się Państw co do uznania i uszanowania praw dla pewnych dziedzin.

5. Do protokołów podkomisyj Konferencji Genewskiej nie można przy interpretacji Konwencji przywiązywać znaczenia decydującego.

Kaschny:

Wypowiedzenie przez państwo na podstawie umowy prywatnoprawnej nie jest ,postanowieniem" państwa w rozumieniu art. 4 \& L. 3.

Frystatzki :

1. Niema zobowiązania państwa obejmującego pewne terytorjum do przejęcia urzędników na tem terytorjum zatrudnionych.

2. W Konwencji Genewskiej niema zadnego postanowienia o przejęciu urzędników pocztowych.

Dr. Bruck :

1. Czynności prawne władzy, leżace $w$ dziedzinie prawa prywatnego, moga wykraczać przeciwko postanowieniom publiczno-prawnym, ustanowionym $w$ celu ochrony uprawnionych do zachowania zamieszkania.

2. Przez dopuszczenie do zakładów publicznych należy rozumieć nie tylko prawo korzystania $z$ tych zakladów, lecz takze i prawo wykonywania czynności w tych zakładach.

Halamoda :

Pojęcie zamieszkania $\mathrm{z}$ art. 29 jest określone przez ogól działalności osobistej i gospodarczej oraz stosunkow osobistych i gospodarczych, pojętych jako całosc.

Ostrowski :

1. Obowiazek przejęcia przez Polskę bezpośrednich urzędników państwowych w Konwencji Genewskiej nie jest ustalony.

2. Z braku wyraźnej umowy nie istnieje w myśl prawa międzynarodowego obowiązek przejęcia urzędników odstąpionego terytorjum.

Wolln y :

1. Wyliczenie zawodów $w$ art. $4 \S 2$ jest wyczerpujące $i$ nie dopuszcza rozszerzenia.

2. Badanie mięsa nie jest przemyslem koncesjonowanym. Zajmowanie się badaniem mięsa wymaga dowodu uzdoInienia, jednakże uzyskanie go nie uprawnia jeszcze do wykonywania tego zawodu.

3. Do rozpoznawania zarzutu naruszenia prawa mniejszości Trybunał Rozjemczy dla Górnego Śląska nie jest właściwym.

Musiolik:

Art. 544 Konwencji może być zastosowany jedynie do takich urzędników kolejowych, którzy przed przejściem na stałe do polskiej służby państwowej byli poprzednio urzędnikami czasowymi w rozumieniu art. 501 i nast. Konwencji.

Oppersdorff:

Deklaracja opcyjna, która wpłynęła do wlaściwego urzędu dopiero po dokonaniu odwołania, nie ma żadnych skutków prawnych.

Gruschka :

1. Istotę opcji stanowi deklaracja osoby optującej. 


\section{$-\mathrm{XI}-$}

2. Następstwem złożenia ważnej deklaracji opcyjnej jest zmiana obywatelstwa. Wręczenie aktu opcji oznacza chwile, w której stwierdzenie ważności opcji ujawnia się na zewnątrz. Niepodjęcie aktu opcji jest dla ważności opcji bez znaczenia.

Neumann:

Zmiana obywatelstwa męża rozciąga się nie tylko na zone (art. 31), lecz również i na jej małoletnie dzieci z poprzedniego małżeństwa, pozostajace $\mathrm{z}$ nią we wspólnem gospodarstwie.

Folger:

Konwencja Genewska normując kwestje obywatelstwa żony nie przywiazywwała do istnienia wspólności małzeńskiej znaczenia decydujacego.

Irrek:

1. Do postępowania zmierzającego do ustalenia obywatelstwa a opartego na Konwencji Wiedeńskiej Trybunał Rozjemczy dla Górnego Ślaska nie jest właściwym.

2. Przy badaniu warunków prawa zachowania zamieszkania Try. bunal Rozjemczy dla Górnego Sląska jest właściwym również i do rozpoznawania zagadnienia incydentalnego co do zastosowania innych ustaw poza Konwencją Genewska. jest wlaściwym.

3. Do udzielania zezwoleń na pobyt Trybunał Rozjemczy nie

Jonek:

Celem utworzenia Komisji Polubownej jest załatwianie sporów; spór jest załatwiony, gdy strony interesowane godza się na odnośne zalatwienie sprawy przez Komisję Polubowną. Przez ,strony interesowane" rozumieć należy wnioskodawcę $\mathrm{i}$ władzę nieuznająca jego pretensyj.

Kianek:

1. Uchwała, w której sąd (władza administracyjna) potwierdził pytanie, że rozstrzygnięcie jego jest zależne od wykładni artykułu Konwencji Genewskiej, nie podlega ponownemu rozpoznawaniu przez Trybunat Rozjemczy.

2. Gdy z przedstawionego $w$ stanie rzeczy pisma ewokacyjnego wynika, że zażądano wykładni postanowień Konwencji Genewskiej, Trybunał Rozjemczy jest wlaściwym do udzielenia odpowiedzi na odnośne pytania.

3. Wyliczenie ,płodów naturalnych"w art. 218 jest wyczerpujące.

4. Wolność od cła umówiona w art. 218 \$ 1 Konwencji Genewskiej nie obejmuje wolności wwozu. 
